\title{
Distinct changes in CREB phosphorylation in frontal cortex and striatum during contingent and non-contingent performance of a visual attention task
}

\author{
Laura Pozzi, Giuseppina Sacchetti, Laura Agnoli, Pierangela Mainolfi, Roberto W. Invernizzi and Mirjana \\ Carli*
}

Laboratory of Neurochemistry and Behaviour, Department of Neuroscience, Institute for Pharmacological Research "Mario Negri", Milano, Italy

\section{Edited by:}

Gilberto Fisone, Karolinska Institutet,

Sweden

Reviewed by:

Riccardo Brambilla, San Raffaele

Scientific Institute and University, Italy

Andres Ozaita, Universitat Pompeu

Fabra, Spain

*Correspondence:

Mirjana Carli, Laboratory of Neurochemistry and Behaviour,

Department of Neuroscience, Institute for Pharmacological

Research "Mario Negri", via Giuseppe

La Masa 19, Milano 20156, Italy.

e-mail:mirjana@marionegri.it
The cyclic-adenosine monophosphate response element-binding protein (CREB) family of transcription factors has been implicated in numerous forms of behavioral plasticity. We investigated CREB phosphorylation along some nodes of corticostriatal circuitry such as frontal cortex (FC) and dorsal (caudate-putamen, $\mathrm{CPu}$ ) and ventral (nucleus accumbens, NAC) striatum in response to the contingent or non-contingent performance of the five-choice serial reaction time task (5-CSRTT) used to assess visuospatial attention. Three experimental manipulations were used; an attentional performance group (contingent, "master"), a group trained previously on the task but for whom the instrumental contingency coupling responding with stimulus detection and reward was abolished (noncontingent, "yoked") and a control group matched for food deprivation and exposure to the test apparatus (untrained). Rats trained on the 5-CSRTT (both master and yoked) had higher levels of CREB protein in the FC, CPu, and NAC compared to untrained controls. Despite the divergent behavior of "master" and "yoked" rats CREB activity in the FC was not substantially different. In rats performing the 5-CSRTT ("master"), CREB activity was completely abolished in the CPu whereas in the NAC it remained unchanged. In contrast, CREB phosphorylation in CPu and NAC increased only when the contingency changed from goal-dependent to goal-independent reinforcement ("yoked"). The present results indicate that up-regulation of CREB protein expression across cortical and striatal regions possibly reflects the extensive instrumental learning and performance whereas increased CREB activity in striatal regions may signal the unexpected change in the relationship between instrumental action and reinforcement.

Keywords: CREB, frontal cortex, caudate-putamen, nucleus accumbens, attention, goal-directed action, arousal, instrumental contingency

\section{INTRODUCTION}

Selective and sustained attention in experimental animals (mostly rats and mice but recently also monkeys) can be measured by the five-choice serial reaction time task (5-CSRTT; Robbins, 2002) which in its basic form is akin to the continuous performance tests of Rosvold and Mirsky (Rosvold et al., 1956; Mirsky and Rosvold, 1960) much used in clinical settings to quantify attention deficit in attention deficit hyperactivity disorder (ADHD) and schizophrenia and which assesses sustained attention to a number of distinct locations over a 30-min or so test session. The task has also analogies to the 5-CSRTT (Wilkinson, 1963), in which human subjects had to continuously monitor the location of visual target stimuli over repeated trials in one of the five spatially diverse locations. The task thus has elements of continuous performance test, but also has an obvious component of selective spatial attention.

The basic 5-CSRTT essentially tests the ability of the rat to sustain spatial attention divided among five locations over a large number of trials. The attentional performance is measured by the accuracy of visual discrimination, omissions, speed of responding, and by different indices of response inhibitory control (sometimes called executive functioning) such as premature and perseverative responses (see Robbins, 2002 for a detailed description and discussion of these performance measures). Following extensive training on the 5-CSRTT, performance generally reaches high and stable levels over time, with low within and between-subject variance. These characteristics of the task are well suited for studies of neural bases of selective attention in animals and have been exploited in numerous lesion and neuropharmacological studies (for a review of these studies see Robbins, 2002; Dalley et al., 2004, 2011; Chudasama and Robbins, 2006). Few studies have attempted to correlate rats' performance during the 5-CSRTT with neurotransmission such as that of acetylcholine $(\mathrm{ACh})$, noradrenaline (NE), and serotonin (5-HT; Passetti et al., 2000; Dalley et al., 2001, 2002) or metabolic activity in cortical regions (Barbelivien et al., 2001). However, despite the wealth of data implicating specific neurotransmitters in the control of different aspects of performance in the 5-CSRTT, the postsynaptic signaling mechanisms that lie behind such performance are largely unexplored.

The cyclic-adenosine monophosphate response elementbinding protein (CREB) family of transcription factors are 
activated via phosphorylation on its serine ${ }^{133}\left(S^{133}\right)$ and have been implicated in a variety of functions. CREB phosphorylation is increased by exposure to a novel environment (Vianna et al., 2000), contextual fear conditioning (Impey et al., 1998; Stanciu et al., 2001), inhibitory avoidance (Bernabeu et al., 1997), and radial and Morris maze training and performance (Mizuno et al., 2002; Porte et al., 2008). Changes in CREB phosphorylation in hippocampus or dorsal striatum have been shown to depend on whether rats use place or response strategy to solve the cross maze (Colombo et al., 2003). Sustained down-regulation in CREB function by viral vector delivery of dominant negative form of CREB (mCREB) impaired accuracy in the 5-CSRTT (Paine et al., 2009) while its over-expression in the orbitofrontal cortex increased impulsivity in a forced-choice task (Sun et al., 2010).

To study the relationship between CREB function and attention performance in the 5-CSRTT, immediately after the end the task we measured by western blot the phosphorylation of CREB protein on $\mathrm{S}^{133}$ ( $\mathrm{p}$-CREB) in prefrontal cortex (PFC), caudateputamen $(\mathrm{CPu})$, and nucleus accumbens (NAC). These brain areas were chosen as previous studies have shown that they are critically involved in aspects of rats' performance in the 5-CSRTT (Muir et al., 1996; Christakou et al., 2001, 2004; Rogers et al., 2001; Passetti et al., 2002; Chudasama et al., 2003a,b). To control for the impact of reward processes to the action-outcome associations (Dickinson and Balleine, 1994) that underlie the rats' performance in the 5-CSRTT in one group of rats we degraded the instrumental contingency inherent in the task by making the reinforcement contingent on the performance of a second animal. Therefore our experimental design had three populations of rats (see Table 1 for a summary of behavioral procedures). The first group of rats "untrained" which served as control for extended food deprivation and the effects of training and/or performing the task, was food deprived and habituated to the same testing chamber but no stimuli were ever presented or food reward delivered. The second, an attentional performance group of rats "master" (or contingent subjects) performed the task as usual whereas the third group of rats "yoked" (or non-contingent subjects) experienced the stimuli and rewards as being earned by their corresponding master rat; while their own actions had no consequences. The actionoutcome contingency was therefore maintained for the master, but severely degraded for the yoked (examples are illustrated in

Table 1 | Summary of behavioral procedures.

\begin{tabular}{|c|c|c|c|}
\hline & \multicolumn{2}{|c|}{ Trained } & \multirow{2}{*}{$\begin{array}{l}\text { Untrained } \\
\text { Food } \\
\text { deprivation }\end{array}$} \\
\hline $\begin{array}{l}\text { Phase } 1 \text { (40-50 } \\
\text { sessions) }\end{array}$ & $\begin{array}{l}\text { Food deprivation } \\
\text { the } 5 \text {-CSRTT (100 }\end{array}$ & $\begin{array}{l}\text { nd training on } \\
\text { trial or } 30 \mathrm{~min} \text { ) }\end{array}$ & \\
\hline $\begin{array}{l}\text { Phase 2, } 7 \text { days, } \\
\text { stable } \\
\text { performance }\end{array}$ & $\begin{array}{l}\text { 5-CSRTT (100 } \\
\text { trials or } 30 \mathrm{~min} \text { ) }\end{array}$ & $\begin{array}{l}5 \text {-CSRTT (100 } \\
\text { trials or } \\
30 \mathrm{~min})\end{array}$ & $\begin{array}{l}\text { Habituation } \\
\text { (house light } \\
\text { on; } 30 \mathrm{~min} \text { ) }\end{array}$ \\
\hline $\begin{array}{l}\text { Phase } 3 \text {, one } \\
\text { session, } \\
\text { experiment }\end{array}$ & $\begin{array}{l}\text { 5-CSRTT Master } \\
\text { (200 trials; } \\
30 \mathrm{~min} \text { ), } n=7\end{array}$ & $\begin{array}{l}\text { 5-CSRTT Yoked } \\
\text { (200 trials; } \\
30 \mathrm{~min} \text { ), } n=7\end{array}$ & $\begin{array}{l}\text { Exposure } \\
\text { (house light on; } \\
30 \text { min), } n=7\end{array}$ \\
\hline
\end{tabular}

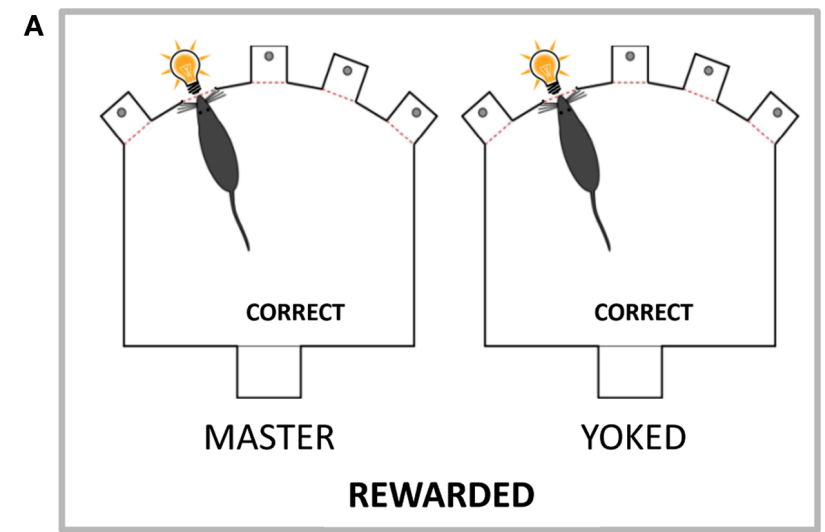

B

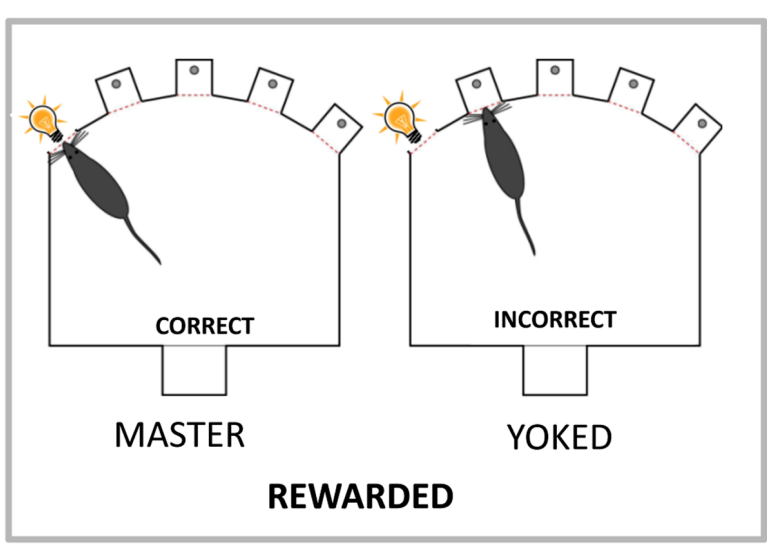

C

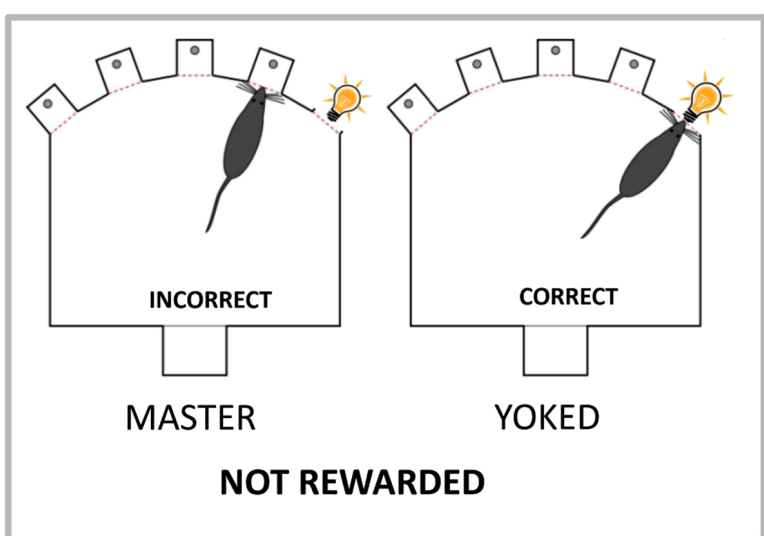

FIGURE 1 |The yoked animal receives stimuli and rewards not according to its behavior but according to the behavior of its master partner. Schematic representation of the box used to run the 5-CSRT task, with five holes set in a curved wall and a visual stimulus (light bulb; presented at random in one of the five holes for $0.5 \mathrm{~s}$ ). One the opposite wall is set the food magazine where the earned food pellets are delivered. The master and yoked rats have three possible outcomes. (A) Both master and yoked rats respond in the hole with stimulus on (correct response), and both are rewarded by food. (B) Master rat responds in the hole with stimulus (correct response) while yoked rat responds in a non-stimulus hole (incorrect response). As master rat gained a food pellet for its correct response, the yoked rat is also rewarded by food. (C) Master rat makes nose poke in a non-stimulus hole (incorrect response) whereas yoked rat makes a nose poke in the stimulus hole (correct response). As master rat made an incorrect response which is not rewarded the yoked rat is not rewarded either 
Figure 1). Subjects in the yoked group could engage in the task and receive the same number of rewards as their master partners but were no longer rewarded for correct responses.

\section{MATERIALS AND METHODS SUBJECTS}

Twenty-four male Hooded Lister rats (Charles River, Italy) were used. The rats weighed $280-320 \mathrm{~g}$ at the start of the experiments, and were housed in pairs until surgery, under temperaturecontrolled conditions $\left(21^{\circ} \mathrm{C}\right)$ with a day/night cycle (light on 7:00 am-7:00 pm). Limited access to food (about $15 \mathrm{~g}$ of Altromin pellets for rats) at the end of each day's testing kept the animals at about $90 \%$ of their free-feeding weight. Water was available ad libitum.

Procedures involving animals and their care were conducted in conformity with the institutional guidelines that are in compliance with the national (D.L. n. 116, G.U., suppl., 40, 18 Febbraio 1992, Circolare No. 8, G.U., 14 luglio 1994) and international laws and policies (EEC Council Directive 86/609, OJ L 358,1, December 12, 1987; Guide for the Care and Use of Laboratory Animals, US National Research Council, 1996).

\section{BEHAVIORAL PROCEDURES}

All rats were food deprived for the same period of time (about 3 months). Two groups of rats received different forms of training (see Table 1 for a summary of behavioral procedures). The rats in the first group $(n=7)$ were habituated to the testing chamber for 7 days preceding the experimental day, but no stimuli were ever presented or food delivered; untrained controls. During these habituation sessions rats were kept with the light on in the test boxes for $30 \mathrm{~min}$.

The second group of rats $(n=14)$ was trained in the 5-CSRTT. The apparatus consisted of four specially designed boxes (Campden Ins., UK) controlled on-line by Whisker software (Cambridge University Technical Services, Ltd., UK). The apparatus and all the details of training procedures have been described previously (Carli et al., 1983).

Briefly, rats were trained to wait for a fixed time $(5 \mathrm{~s})$ before a brief visual stimulus $(0.5 \mathrm{~s})$ was presented in one of the five holes. While the light was on, and for a short period afterward (limited hold), response in the hole that was illuminated (correct response) resulted in the delivery of a food pellet ( $45 \mathrm{mg}$ Sandown Scientific, UK). Responses in the holes that had not been illuminated (incorrect responses) or failure to respond within the limited hold (omissions) caused a time-out (the house light was turned off for $2 \mathrm{~s}$ ). Anticipatory responses (responses made before presentation of the visual stimulus during the 5-s of the waiting period) and perseverative responses (responses repeated in the holes after a correct or incorrect response but before collecting the food pellet) caused a time-out. After an anticipatory response the current trial was restarted. Each daily session consisted of 100 trials or $30 \mathrm{~min}$ of testing, whichever was completed sooner. Each rat had only one session per day on the 5-CSRTT.

When rats reached a stable performance with a mean of $>80 \%$ correct responses, $<20 \%$ omissions, at stimulus duration of $0.5 \mathrm{~s}$ they were assigned to two performance groups master and yoked. During the next seven training days baseline performance was recorded to ensure that both groups were evenly matched. However, only on the day of the experiment were the yoked rats actually yoked to the execution of the 5-CSRT task by their master partners. The dependent variables selected for analysis were: (a) accuracy of visual discrimination expressed as the percentage of correct responses (total correct responses/total correct + total incorrect responses $\times 100$ ); (b) percentage of omissions (total omissions/total correct + total incorrect + total omissions $\times 100)$; (c) the number of premature responses in the holes during the ITI); (d) the number of perseverative responses in the holes after a correct or an incorrect response; and (e) the number of perseverative panel pushes. We also recorded (to the nearest $0.001 \mathrm{~s}$ ) and analyzed (e) mean correct response latency; (f) mean incorrect response latency; and ( $\mathrm{g}$ ) the mean latency to collect the earned food pellet.

On the day of experiment the yoked rats were to receive the same visual stimuli and reward as their paired master subjects, but their action would lead to no programmed consequences (see Figure 1 for a schematic representation of the contingency coupling for master and yoked subjects). As the well-trained rats complete 100 trials in less than $30 \mathrm{~min}$, the number of trials during the experiment was increased to 200 to equate the time of decapitation ( $30 \mathrm{~min}$ from the start of the task) for all rats. The experiment was run on two consecutive days between 9 and 12 am. On each day four triplets of one untrained, one master, and one yoked rat were run.

\section{SAMPLES PREPARATION}

Immediately after the end of the behavioral test rats were killed by decapitation their brains quickly removed and immediately immersed in ice-cold saline for few seconds. The frontal cortex (FC; comprising prefrontal, orbitofrontal, cingulate, and primary motor cortex), $\mathrm{CPu}$, and the NAC were rapidly dissected out, immediately frozen on dry ice and stored until use. Tissues were homogenized by sonication (Sonopuls, Bandelin electronic, Germany; power 30\%, cycle 30\%, 10-15 pulses) in $1 \mathrm{ml}$ (FC and CPu) or $0.5 \mathrm{ml}$ (NAC) of $1 \%$ sodium dodecyl sulfate (SDS), heated for $10 \mathrm{~min}$ at $95^{\circ} \mathrm{C}$ and centrifuged at $5000 \mathrm{~g}$ for $2 \mathrm{~min}$. Supernatant fractions obtained from all tissues of interest were prepared on the same day and stored at $-80^{\circ} \mathrm{C}$ until they were analyzed by immunoassay. Each brain region was processed separately. Immunoblots of $\mathrm{p}$-CREB, CREB, and $\beta$-actin were obtained from the same sample but run on different gels.

\section{WESTERN BLOT ANALYSIS}

The concentration of total proteins in the supernatant of each sample was measured by the bicinchoninic acid protein assay method (BCA protein assay kit, Pierce Biotechnology, USA). Equal amounts of protein extracts $(20 \mu \mathrm{g})$ were loaded onto multiwell combs enabling 14 samples to be loaded onto the same gel. To minimize the inter-blot variability, three to four samples for each experimental group were loaded onto the same gel. In a separate well, $5 \mu \mathrm{l}$ of dual-color pre-stained molecular mass marker (Precision Plus Protein ${ }^{\mathrm{TM}}$ Standards; Bio-Rad, Italy) was loaded for molecular weight determination. Proteins were separated by $10 \%$ SDS-polyacrylamide gel electrophoresis at constant current $(50 \mathrm{~mA})$ and room temperature. Proteins 
were transferred onto $0.45 \mu \mathrm{m}$ pore size polyvinylidene fluoride membrane (Amersham GE Healthcare, UK) at $300 \mathrm{~mA}$ and $4^{\circ} \mathrm{C}$ for $1 \mathrm{~h}$. Membranes were blocked with 5\% non-fat milk in TBS$\mathrm{T}(0.05 \%$ Tween 20 in Tris-buffered saline, $\mathrm{pH}$ 7.6). The blots were then incubated overnight at $4^{\circ} \mathrm{C}$ with primary antibodies against phospho- $\mathrm{S}^{133} \mathrm{CREB}$ (anti-mouse monoclonal, 1:5000, Upstate Biotechnology, USA), CREB (anti-mouse monoclonal, 1:5000, Cell Signaling Technology, USA), and $\beta$-actin (anti-rabbit polyclonal, 1:8000, Cell Signaling Technology, USA) in TBS-T with $2 \%$ bovine serum albumin. The next day, after 5 five-min rinses with TBS-T, membranes were incubated for $1 \mathrm{~h}$ at room temperature with anti-mouse (1:8000 for p-CREB and CREB; Santa Cruz Biotechnology, USA) or anti-rabbit (1:10000 for $\beta$-actin; Cell Signaling Technology, USA) HRP-conjugated IgG peroxidase-labeled secondary antibodies.

The immunopositive protein bands were detected with a chemiluminescent home made ECL luminol/p-coumaric acid solution. Membranes were exposed in the dark room to autoradiography films (Hyperfilm ECL, Amersham GE Healthcare) then developed. Densitometric analysis of immunoblots was done to quantify the changes in protein levels using the public domain ImageJ (http://rsbweb.nih.gov/ij/). The optical density of the band for each antibody was linear in the range between 15 and $60 \mu \mathrm{g}$ total protein/well as calculated by linearity tests (not showed).

\section{STATISTICAL ANALYSIS}

Differences in the number of correct responses, the number of omissions, and the number of perseverative panel pushes as well as the mean latency to collect the earned food pellet between "master" and "yoked" rats were assessed by unpaired Student's $t$-test (StatView 5.0 software). The analysis of quantitative data from western blot assays, expressed as mean percentage of untrained controls, was done by one-way ANOVA (StatView 5.0 software) and between groups comparison made by Tukey's test.

To account for changes in total CREB, p-CREB levels were expressed as the ratio of $\mathrm{p}-\mathrm{CREB} / \mathrm{CREB}$ optical densities. Then, values obtained in untrained, master, and yoked rats were divided by mean values of untrained rats. These ratios (untrained, U/U; master, M/U; and yoked, Y/U) were analyzed by one-way ANOVA followed by Tukey's test, which compared the task condition means between them.

\section{RESULTS}

\section{BEHAVIOR OF MASTER AND YOKED RATS IN THE 5-CSRTT}

When a rat perform an action for a rewarding outcome it does so via several psychological mechanisms one being "goal-directed" action analogous to the human concept of intention. Thus when the rat in the 5-CSRTT responds to a visual stimulus, among several reasons it may do it because it has learned the contingency between its action and the outcome. With extended training necessary for the optimal performance in the 5-CSRTT, actions that were originally "goal-directed" could become "automatic" and habitual. Habits (i.e., stimuli evoke directly a motor response) are relatively inflexible and require fewer cognitive resources that goal-directed actions. We predicted that if the rats were not responding habitually during the 5-CSRTT the yoked rats were expected to swiftly shift their responses from responding in the stimulus holes to the food source.

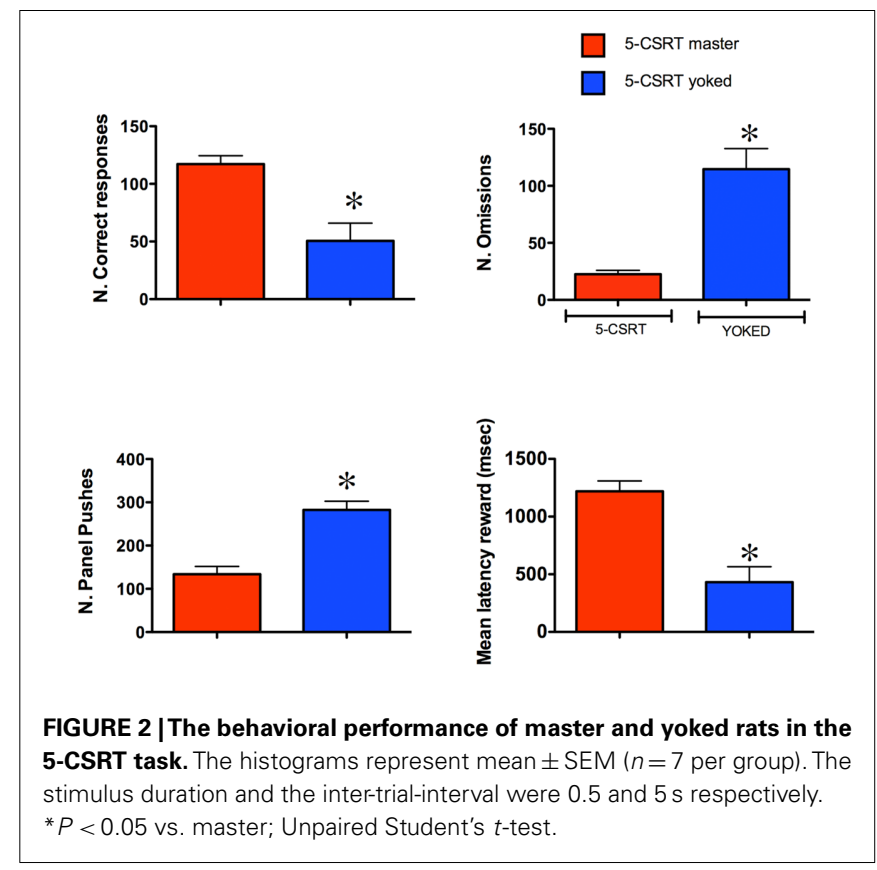

Figure 2 shows the comparative effects of degrading the instrumental contingency on the behavior of master and yoked subjects on the 5-CSRTT. Analysis of total number of correct responses revealed that yoked rats made fewer correct responses and a higher number of omissions than master subjects (both $P<0.05$; unpaired Student's $t$-test). Magazine entries (panel pushes) were almost twice as frequent in yoked animals compared to master subjects $(P<0.05$; unpaired Student's $t$-test $)$ and yoked animals collected the reward much faster than master rats $(P<0.05$; unpaired Student's $t$-test). However, on trials in which yoked subjects made a response, they did it as accurately $(83.4 \pm 4.3 \%$ correct $)$, as their master partners $(86.7 \pm 1.2 \%$ correct $)$, and with similar correct response latency (master $0.72 \pm 0.03 \mathrm{~s}$; yoked $0.66 \pm 0.03$ ). Overall, these behavioral data show that yoked subjects very rapidly extinguished responding for target stimuli and that they directed their activity toward the food source (magazine).

\section{P-CREB AND CREB EXPRESSION IN UNTRAINED AND MASTER AND YOKED RATS}

Figure 3 shows the intensity of CREB and p-CREB signal in immunoblots obtained from the $\mathrm{FC}, \mathrm{CPu}$, and NAC of representative untrained $(\mathrm{U})$ master $(\mathrm{M})$ and yoked $(\mathrm{Y})$ subjects.

The mean values of $\mathrm{p}$-CREB and CREB protein levels, expressed as percentages of untrained control rats are shown in Figure 4. We found a statistically significant differences in p-CREB (FC, $F_{2,17}=10.3 P<0.001$; CPu, $F_{1,8}=5.5 P<0.001$; NAC, $\left.F_{2,13}=48,7 P<0.0001\right)$ and CREB levels $\left(\mathrm{FC}, F_{2,18}=18.3\right.$ $P<0.0001 ; \mathrm{CPu}, F_{2,16}=22.1 \quad P<0.0001 ; \mathrm{NAC}, F_{2,18}=73.0$ $P<0.0001)$ in master and yoked compared to untrained controls across the corticostriatal regions examined. p-CREB levels in the FC of master and yoked rats were significantly higher than in untrained rats ( $P<0.05$ vs. untrained; Tukey's test), reaching about $300 \%$ in both groups. p-CREB levels were undetectable or strongly reduced in the $\mathrm{CPu}$ of master rats. By contrast, $\mathrm{p}$-CREB 


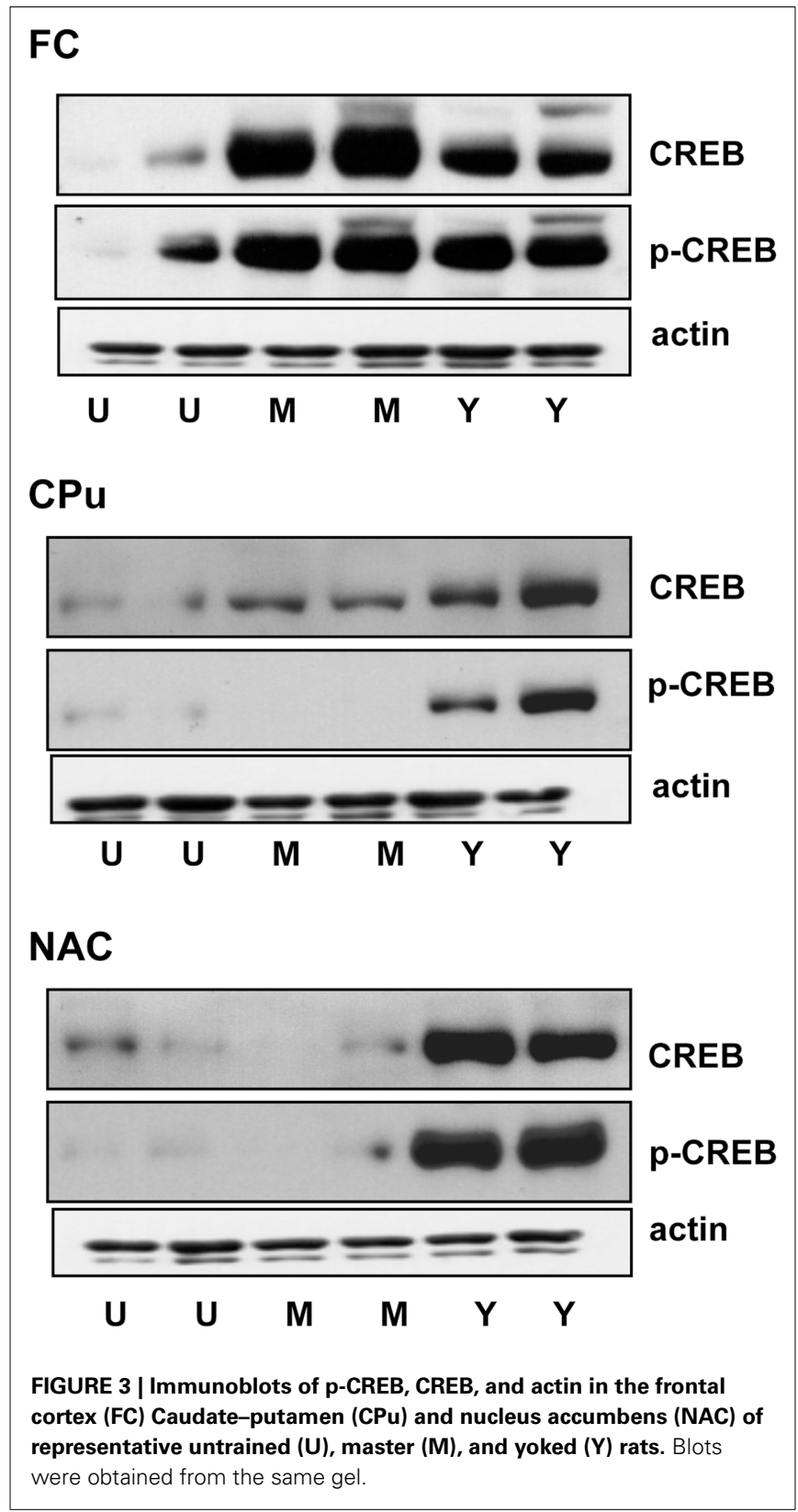

increased by about 10 -folds in the $\mathrm{CPu}$ of yoked rats $(P<0.05$ vs. untrained; Tukey's test). The increase in p-CREB levels was even larger in the NAC of yoked rats, reaching almost $2000 \%$ of untrained controls $(P<0.05$ vs. untrained and master; Tukey's test), while no significant changes were observed in the NAC of master rats.

Total CREB (unphosphorylated plus phosphorylated) levels were significantly increased in the $\mathrm{FC}$ and $\mathrm{CPu}$ of master rats (both $P<0.05$ vs. untrained; Tukey's test) whereas no significant changes were observed in the NAC. In yoked rats, CREB increased in all brain regions examined. The effect was stronger in the NAC, reaching about $700 \%(P<0.05$ vs. untrained or master rats; Tukey's test). In the FC of yoked rats CREB levels increased by $400 \%$ and this increase was significantly less than in master rats
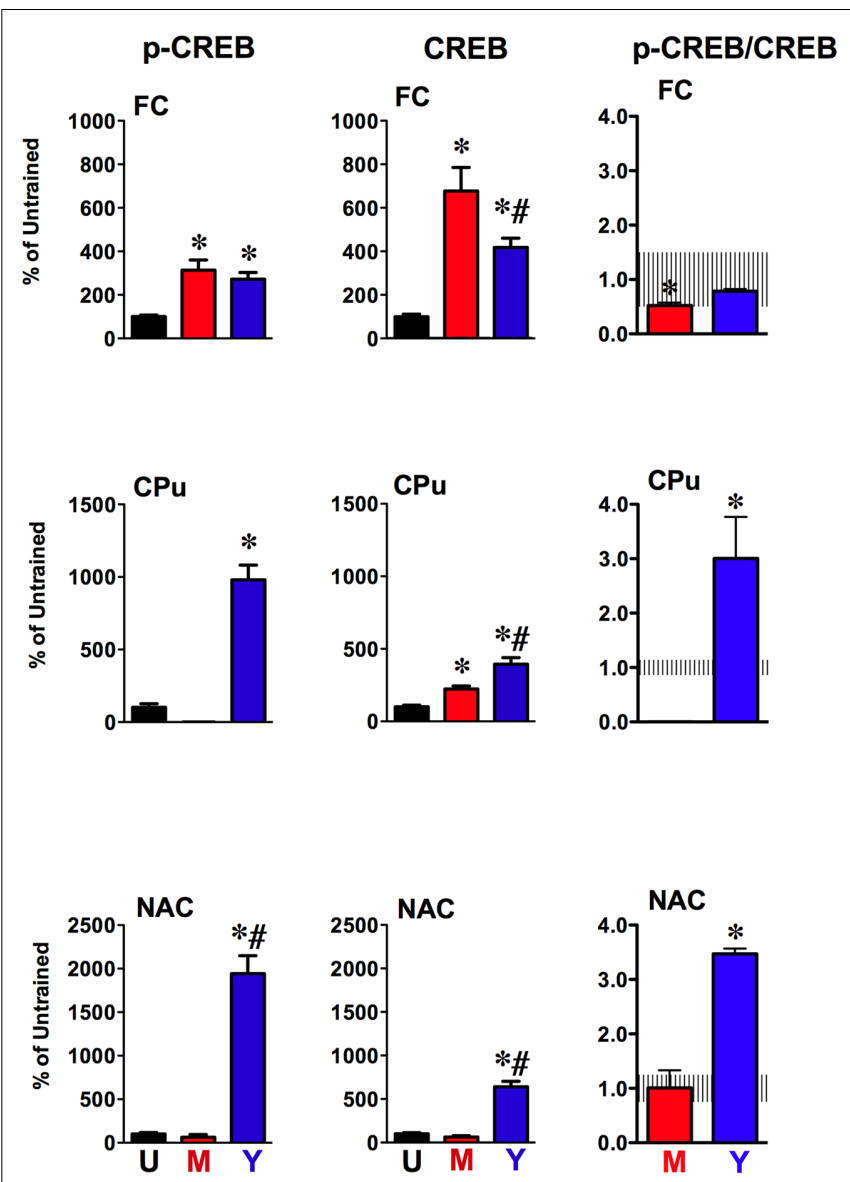

\footnotetext{
$*_{p}<0.05$ vs $U$ (Tukey's test)

\# $\mathrm{p}<0.05$ vs $\mathrm{M}$ (Tukey's test)
}

FIGURE 4 | Quantification of p-CREB and CREB levels and p-CREB/CREB ratios in the frontal cortex (FC) Caudate-putamen (CPu) and nucleus accumbens (NAC) of untrained (U), master (M), and yoked (Y) rats. Data are expressed as the percentage of protein level in untrained control rats. Histograms represent mean \pm SEM of six to seven rats per group. The shaded areas represent the mean $\pm S D$ of $p-C R E B / C R E B$ ratios for untrained control rats. ${ }^{*} P<0.05$ vs. untrained $(U) ; \# P<0.05$ vs. master (M); Tukey's test.

(700\%; $P<0.05$ vs. master; Tukey's test) whereas in the $\mathrm{CPu}$ the increase in CREB signal was larger in yoked compared to master rats $(P<0.05$; Tukey's test). In all brain regions examined, actin levels (Figure 3 ) did not change across experimental groups.

The ratios of $\mathrm{p}$-CREB/CREB are reported in Figure 4 . The mean $\pm S D$ ratio for untrained rats was $1.00 \pm 0.54$ in $\mathrm{FC}$; $1.00 \pm 0.14$ in $\mathrm{CPu}$ and $1.00 \pm 0.25$ in NAC and are shown as the shaded areas in Figure 4. One-way ANOVA revealed significant differences across groups in $\mathrm{p}$-CREB/CREB ratios in the PFC $\left(F_{2,18}=3.5, P=0.05\right) \mathrm{CPu}\left(F_{1,8}=243.4, P<0.0001\right)$ and $\operatorname{NAC}\left(F_{2,13}=83.0, P<0.0001\right)$. Post hoc analysis showed that $\mathrm{p}$-CREB/CREB ratio in master rats was actually decreased to about $52 \%$ of untrained rats $(P<0.05$; Tukey's test $)$ whereas that 
of yoked rats was $73 \%$ of untrained controls $(P>0.05$; Tukey's test). The $\mathrm{p}$-CREB/CREB ratio of master and yoked rats was not significantly different $(P>0.05$; Tukey's test). The ratio $\mathrm{p}$ CREB/CREB was strongly increased in the $\mathrm{CPu}(+200 \%)$ and NAC ( $+248 \%)$ of yoked rats (both $P<0.05$ vs. untrained; Tukey's test). No significant changes were observed in the NAC of master rats. The ratio $\mathrm{p}-\mathrm{CREB} / \mathrm{CREB}$ in the $\mathrm{CPu}$ of master rats was not calculated because p-CREB levels were not detectable in most samples.

\section{DISCUSSION}

This study is the first to measure p-CREB and CREB protein levels along different nodes of prefrontal corticostriatal circuitry in rats that performed a visuospatial attentional task such as 5CSRTT. The main finding was that rats performing the 5-CSRTT were able to detect instrumental contingency change and adapt the performance accordingly suggesting that their performance was goal-directed and not "automatized" or habitual (Balleine and Dickinson, 1998; Yin et al., 2008). The behavioral changes in subjects experiencing a non-contingent reward (yoked rats) were associated with increased CREB phosphorylation in all areas examined. In contingent subjects (master rats), who performed the 5-CSRTT as usual, to an increase in p-CREB in the FC corresponded a decrease in the $\mathrm{CPu}$ and no changes in the NAC. Compared to food-deprived untrained control rats, never exposed to the 5-CSRTT training, there was a substantial increase in total CREB protein levels in master and yoked rats across all areas examined save in the NAC of master rats, suggesting that sustained behavioral experience may increase CREB protein synthesis. These data indicate an anatomical dissociation of psychological functions and their underlying CREB signaling mechanisms that guide rats' performance in the 5-CSRTT.

Master rats performed the task with high efficiency missing only few stimuli. By contrast yoked rats' performance toward the target stimuli was rapidly extinguished as shown by substantial decrease in the number of correct responses and an increase in the number of responses directed toward the food source, which were also much faster than in master rats. This switch in responding from nose-pokes in stimulus holes to panel pushes is an indication of rats' ability to shift their attention to a more reliable predictor of reward. In the FC of master and yoked rats $\mathrm{p}$-CREB was increased to the same level. However, these changes were largely compensated by the up-regulation of total CREB in both master and yoked compared to untrained rats indicating that there was not a real increase in p-CREB as shown by $\mathrm{p}$-CREB/CREB ratios. Thus, despite the divergent behavior in master and yoked rats, their $\mathrm{p}$-CREB/CREB ratios were not substantially different implying no behavioral selectivity of CREB activation in this brain region. Functional specialization of frontocortical regions and corticostriatal circuits has been described for the 5-CSRTT and thus it could not be excluded that various aspects or types of performance might affect CREB function differentially in various frontocortical regions (Muir et al., 1996; Christakou et al., 2001, 2004; Rogers et al., 2001; Passetti et al., 2002; Chudasama et al., 2003b). It should be noted that we cannot distinguish the CREB activity in these specialized PFC regions as we have measured CREB function in the frontal pole comprising PFC, orbitofrontal, cingulate, and pre-motor areas and thus our measure reflects the resultant activity in this cortical area.

The most compelling finding of this investigation is that of differences in CREB activation across the FC, $\mathrm{CPu}$, and NAC between yoked and master rats. This finding specifies the conditions that engage this signal transduction system in these brain areas. Thus increased $\mathrm{p}-\mathrm{CREB} / \mathrm{CREB}$ ratios in the $\mathrm{CPu}$ and NAC of yoked subjects may signal a mismatch between action and reinforcement. The resulting shift in attention from responding to stimuli that are no more predictive of reward to those perceived as more reliable predictors of the reinforcement (i.e., panel pushes) may be an important mechanism that promotes the new contingency learning in yoked rats. CREB has been shown to positively regulate dorsal striatum-dependent synaptic plasticity, procedural learning, and specific cognitive response-based behavioral strategies (Colombo et al., 2003; Pittenger et al., 2006).

It is interesting to note that rats bearing selective lesions of the NAC are still able to detect the change in the actionoutcome contingency (Balleine and Killcross, 1994; Corbit et al., 2001) thus suggesting that NAC is not necessary for instrumental contingency encoding. Based on traditional two-process theory (Rescorla and Solomon, 1967) that stimuli, which predict an outcome can modulate animals' affective arousal, Balleine and Killcross (1994) have argued that NAC is not directly involved in integrating the information that mediate instrumental action but plays a central role in the way conditioned affective arousal is expressed in performance. Increased CREB activity in the NAC enhances NMDA receptor mediated synaptic transmission (Dong et al., 2006; Huang et al., 2008) and decreases animals' responses to emotionally important stimuli (Barrot et al., 2002). In analogy to finding that activation of CREB in the NAC helps to limit the enhanced responsiveness to repeated cocaine exposure (Carlezon et al., 1998; Pliakas et al., 2001), it could be hypothesized that the increase in p-CREB in the NAC may operate to dampen the negative consequences on behavior by increased levels of arousal induced by the shift in contingency. Interestingly, Christakou et al. (2004) found that the $\mathrm{mPFC} / \mathrm{NAC}$ systems, which do not appear to be involved in the control of executive attention, integrate the information about the consequences of action in relation to anticipated reward and thus modulate the affective/arousing aspects of the 5-CSRTT performance.

The difference in $\mathrm{p}$-CREB/CREB ratios in the $\mathrm{CPu}$ and NAC in master and yoked rats is unlikely to be due to some difference in the level of satiation or consummatory behavior as yoked rats received the same number of food pellets as their master partners. It could be argued that the contingent performance of master rats required a greater degree of executive control to coordinate the behavioral sequence necessary to obtain the reinforcement, which included visual search, detection, and response selection as well as tight organization of motor activity "runs" between the magazine and response holes located on the opposite walls of the operant chamber. Although it cannot be excluded that changes in p-CREB in yoked rats may reflect at least in part the reduced number of stimulus bound response sequences necessary to obtain the reward increased not decreased p-CREB was positively associated with motor activity (Giordano et al., 2010). 
The opposite changes in CREB activity in cortical and striatal regions may reflect differences in molecular signals of frontocortical vs. striatal neurons. Reciprocal regulation of cortical vs. striatal regions is well established, for example for neurotransmitters such as dopamine (Wilkinson et al., 1997); therefore it is unsurprising to find evidence of reciprocal changes in molecular signals in these brain regions. Significant differences in p-CREB between $\mathrm{FC}$ and $\mathrm{CPu}$ in response to electroconvulsive seizures have been reported (Tanis et al., 2008). No changes in p-CREB/CREB ratio were detected in the NAC of master rats whereas in the $\mathrm{CPu}$ of master rats $\mathrm{p}$-CREB/CREB was not calculated because $\mathrm{p}$-CREB signal was abolished in most samples. This dissociation of CREB activation in the $\mathrm{CPu}$ and NAC of contingent subjects is interesting as $\mathrm{mPFC} / \mathrm{CPu}$ but not $\mathrm{mPFC} / \mathrm{NAC}$ appears to control executive attention in the 5-CSRTT (Christakou et al., 2001, 2004).

Compared to untrained controls master and yoked rats which had similar training in the 5-CSRTT procedure had higher levels of total CREB in FC and CPu as well as in the NAC. The lack of changes in total ERK in the same brain areas suggests that there may be some specificity in CREB changes (M. Carli, Unpublished results). The increase in CREB levels possibly reflects instrumental action-outcome learning in this task's procedure. It is worth noting that optimal performance in the 5-CSRTT requires a complex and tightly timed response sequence, which is achieved only after extensive training (2-3 months). As p-CREB and total CREB levels were measured immediately after the behavioral session we are unable to distinguish the effects of instrumental learning from actual task performance. However, it is possible that up-regulation of CREB protein may pre-exist as a result of instrumental learning. Indeed, some studies have shown that there is a spatio-temporal dynamic in CREB activity during learning (Porte et al., 2008) and that consolidation of instrumental performance requires protein synthesis (Hernandez et al., 2002). In analogy to what observed with visual experience (Cancedda et al., 2003) it could be hypothesized that the extensive behavioral experience (i.e., acquisition of instrumental performance) may have increased CRE-dependent genes expression and subsequent CREB synthesis (Meyer and Habener, 1993).

As untrained controls were food deprived and exposed to the operant boxes (but never trained on the 5-CSRTT) it is unlikely that this increase in CREB is due to food deprivation or to exposure to the contextual cues in the operant boxes.

The lack of an increase in total CREB levels in the NAC of master rats is somewhat surprising as CRE-mediated transcription within $\mathrm{NAC}$ is regulated by environmental stimuli and protein synthesis

\section{REFERENCES}

Balleine, B., and Killcross, S. (1994). Effects of ibotenic acid lesions of the nucleus accumbens on instrumental action. Behav. Brain Res. 65, 181-193.

Balleine, B. W., and Dickinson, A. (1998). Goal-directed instrumental action: contingency and incentive learning and their cortical substrates. Neuropharmacology 37, 407-419.
Balleine, B. W., and O'Doherty, J. P. (2010). Human and rodent homologies in action control: corticostriatal determinants of goal-directed and habitual action. Neuropsychopharmacology 35, 48-69.

Barbelivien, A., Ruotsalainen, S., and Sirvio, J. (2001). Metabolic alterations in the prefrontal and cingulate cortices are related to behavioral deficits in a rodent model of attention-deficit hyperactivity disorder. Cereb. Cortex 11, 1056-1063.

in the NAC is necessary for instrumental learning (Hernandez et al., 2002; Huang et al., 2008). This finding would suggest some effect of non-contingent performance on CREB protein levels. In the NAC of yoked rats there was a 20 -fold increase in p-CREB, which in turn may induce its own gene transcription (Meyer and Habener, 1993) although inhibition of CREB protein turnover may have also contributed. However, CREB is a $43-\mathrm{kDa}$ protein and a de novo synthesis in about $30 \mathrm{~min}$ of a such a big protein is unlikely. The antibody used to detect CREB protein levels does not distinguish between unphosphorylated and phosphorylated CREB thus it is likely that the total CREB levels may reflect at least in part the increase in $\mathrm{p}$-CREB.

These data lend additional information to the view that cortical and striatal functions determine the sensitivity of behavior to its consequences (Balleine and Dickinson, 1998; Corbit and Balleine, 2003; Killcross and Coutureau, 2003; Yin et al., 2005, 2008; Lex and Hauber, 2009, 2011). Consistent with this view are also human imaging data showing that action-reward contingency computations activate neural responses in a network of brain regions including the ventromedial PFC, dorsomedial striatum, and the inferior frontal gyrus (Tanaka et al., 2008; Balleine and O'Doherty, 2010; Liljeholm et al., 2011). It is also of particular interest that in rats performing the 5-CSRTT cortical noradrenaline release showed sustained elevations only when contingency was degraded (Dalley et al., 2001). Although the effects of increased neural activity on CREB phosphorylation in corticostriatal circuits has yet to be determined burst of neural activity has been shown to increase p-CREB in hippocampal neurons (Bito et al., 1996). On the other hand, over-expression of CREB in slice culture of the NAC and locus coeruleus (the main source of NE projection to the cortex) neuronal cell types increased membrane excitability (Dong et al., 2006; Han et al., 2006; Huang et al., 2008) whereas decreased CREB activity in the NAC correlated with increased expression of certain $\mathrm{K}^{+}$channels and reduced electrical excitability of NAC neurons (Wallace et al., 2009). Thus it could not be excluded that these differential changes in $\mathrm{p}$ CREB along the nodes of corticostriatal circuits may reflect differences in neuronal activity driven by contingent or non-contingent performance.

In summary the data show that increased CREB activity in striatal regions of yoked rats may signal the unexpected change in the relationship between the instrumental action and reinforcement. In addition, it is possible that up-regulation of CREB protein across cortical and striatal subregions may reflect the extensive instrumental performance acquisition.

Barrot, M., Olivier, J. D., Perrotti, L. I., DiLeone, R. J., Berton, O., Eisch, A. J., Impey, S., Storm, D. R., Neve, R. L., Yin, J. C., Zachariou, V., and Nestler, E. J. (2002). CREB activity in the nucleus accumbens shell controls gating of behavioral responses to emotional stimuli. Proc. Natl. Acad. Sci. U.S.A. 99, 11435-11440.

Bernabeu, R., Bevilaqua, L., Ardenghi, P., Bromberg, E., Schmitz, P., Bianchin, M., Izquierdo, I., and Medina, J. H. (1997). Involvement of hippocampal cAMP/cAMPdependent protein kinase signaling pathways in a late memory consolidation phase of aversively motivated learning in rats. Proc. Natl. Acad. Sci. U.S.A. 94, 7041-7046.

Bito, H., Deisseroth, K., and Tsien, R. W. (1996). CREB phosphorylation and dephosphorylation: a $\mathrm{Ca}(2+)$ - and stimulus durationdependent switch for hippocampal gene expression. Cell 87, 1203-1214. 
Cancedda, L., Putignano, E., Impey, S., Maffei, L., Ratto, G. M., and Pizzorusso, T. (2003). Patterned vision causes CRE-mediated gene expression in the visual cortex through PKA and ERK. J. Neurosci. 23, 7012-7020.

Carlezon, W. A. Jr., Thome, J., Olson, V. G., Lane-Ladd, S. B., Brodkin, E. S., Hiroi, N., Duman, R. S., Neve, R. L., and Nestler, E. J. (1998). Regulation of cocaine reward by CREB. Science 282, 2272-2275.

Carli, M., Robbins, T. W., Evenden, J. L., and Everitt, B. J. (1983). Effects of lesions to ascending noradrenergic neurones on performance of a 5-choice serial reaction task in rats; implications for theories of dorsal noradrenergic bundle function based on selective attention and arousal. Behav. Brain Res. 9, 361-380.

Christakou, A., Robbins, T. W., and Everitt, B. J. (2001). Functional disconnection of a prefrontal corticaldorsal striatal system disrupts choice reaction time performance: implications for attentional function. Behav. Neurosci. 115, 812-825.

Christakou, A., Robbins, T. W., and Everitt, B. J. (2004). Prefrontal cortical-ventral striatal interactions involved in affective modulation of attentional performance: implications for corticostriatal circuit function. J. Neurosci. 24, 773-780.

Chudasama, Y., Baunez, C., and Robbins, T. W. (2003a). Functional disconnection of the medial prefrontal cortex and subthalamic nucleus in attentional performance: evidence for corticosubthalamic interaction. J. Neurosci. 23, 5477-5485.

Chudasama, Y., Passetti, F., Rhodes, S. E., Lopian, D., Desai, A., and Robbins, T. W. (2003b). Dissociable aspects of performance on the 5-choice serial reaction time task following lesions of the dorsal anterior cingulate, infralimbic and orbitofrontal cortex in the rat: differential effects on selectivity, impulsivity and compulsivity. Behav. Brain Res. 146, 105-119.

Chudasama, Y., and Robbins, T. W. (2006). Functions of frontostriatal systems in cognition: comparative neuropsychopharmacological studies in rats, monkeys and humans. Biol. Psychol. 73, 19-38.

Colombo, P. J., Brightwell, J. J., and Countryman, R. A. (2003). Cognitive strategy-specific increases in phosphorylated cAMP response element-binding protein and c-Fos in the hippocampus and dorsal striatum. J. Neurosci. 23, 3547-3554.

Corbit, L. H., and Balleine, B. W. (2003). The role of prelimbic cortex in instrumental conditioning. Behav. Brain Res. 146, 145-157.

Corbit, L. H., Muir, J. L., and Balleine, B. W. (2001). The role of the nucleus accumbens in instrumental conditioning: evidence of a functional dissociation between accumbens core and shell. J. Neurosci. 21, 3251-3260.

Dalley, J. W., Cardinal, R. N., and Robbins, T. W. (2004). Prefrontal executive and cognitive functions in rodents: neural and neurochemical substrates. Neurosci. Biobehav. Rev. 28, 771-784.

Dalley, J. W., Everitt, B. J., and Robbins, T. W. (2011). Impulsivity, compulsivity, and top-down cognitive control. Neuron 69, 680-694.

Dalley, J. W., McGaughy, J., O’Connell, M. T., Cardinal, R. N., Levita, L. and Robbins, T. W. (2001). Distinct changes in cortical acetylcholine and noradrenaline efflux during contingent and noncontingent performance of a visual attentional task. J. Neurosci. 21, 4908-4914.

Dalley, J. W., Theobald, D. E., Eagle, D. M., Passetti, F., and Robbins, T. W. (2002). Deficits in impulse control associated with tonicallyelevated serotonergic function in rat prefrontal cortex. Neuropsychopharmacology 26, 716-728.

Dickinson, A., and Balleine, B. (1994). Motivational control of goaldirected action. Anim. Learn. Behav. 22, 1-18.

Dong, Y., Green, T., Saal, D., Marie, H., Neve, R., Nestler, E. J., and Malenka, R. C. (2006). CREB modulates excitability of nucleus accumbens neurons. Nat. Neurosci. 9, 475-477.

Giordano, T. P., Tropea, T. F., Satpute, S. S., Sinnegger-Brauns, M. J., Striessnig, J., Kosofsky, B. E., and Rajadhyaksha, A. M. (2010). Molecular switch from L-type Ca v 1.3 to $\mathrm{Ca}$ v $1.2 \mathrm{Ca} 2+$ channel signaling underlies long-term psychostimulant-induced behavioral and molecular plasticity. $J$. Neurosci. 30, 17051-17062.

Han, M. H., Bolanos, C. A., Green, T. A., Olson, V. G., Neve, R. L., Liu, R. J., Aghajanian, G. K., and Nestler, E. J. (2006). Role of cAMP response element-binding protein in the rat locus ceruleus: regulation of neuronal activity and opiate withdrawal behaviors. J. Neurosci. 26, 4624-4629.

Hernandez, P. J., Sadeghian, K., and Kelley, A. E. (2002). Early consolidation of instrumental learning requires protein synthesis in the nucleus accumbens. Nat. Neurosci. 5 , 1327-1331.
Huang, Y. H., Lin, Y., Brown, T. E., Han, M. H., Saal, D. B., Neve, R. L., Zukin, R. S., Sorg, B. A. Nestler, E. J., Malenka, R. C., and Dong, Y. (2008). CREB modulates the functional output of nucleus accumbens neurons: a critical role of N-methyl-D-aspartate glutamate receptor (NMDAR) receptors. J. Biol. Chem. 283, 2751-2760.

Impey, S., Smith, D. M., Obrietan, K., Donahue, R., Wade, C., and Storm, D. R. (1998). Stimulation of cAMP response element (CRE)mediated transcription during contextual learning. Nat. Neurosci. 1, 595-601.

Killcross, S., and Coutureau, E. (2003). Coordination of actions and habits in the medial prefrontal cortex of rats. Cereb. Cortex 13, 400-408.

Lex, B., and Hauber, W. (2009). The role of dopamine in the prelimbic cortex and the dorsomedial striatum in instrumental conditioning. Cereb. Cortex 20, 873-883.

Lex, B., and Hauber, W. (2011). Disconnection of the entorhinal cortex and dorsomedial striatum impairs the sensitivity to instrumental contingency degradation. Neuropsychopharmacology 35, 1788-1796.

Liljeholm, M., Tricomi, E., O'Doherty, J. P., and Balleine, B. W. (2011). Neural correlates of instrumental contingency learning: differential effects of action-reward conjunction and disjunction. J. Neurosci. 31, 2474-2480.

Meyer, T. E., and Habener, J. F. (1993). Cyclic adenosine $3^{\prime}, 5^{\prime}$ monophosphate response element binding protein (CREB) and related transcription-activating deoxyribonucleic acid-binding proteins. Endocr. Rev. 14, 269-290.

Mirsky, A. F., and Rosvold, H. E. (1960). "The use of psychoactive drugs as a neuropsychological tool in studies of attention in man," in Drugs and Behavior, eds L. Uhr and J. G. Miller (New York: Wiley), 375-392.

Mizuno, M., Yamada, K., Maekawa, N., Saito, K., Seishima, M., and Nabeshima, T. (2002). CREB phosphorylation as a molecular marker of memory processing in the hippocampus for spatial learning. Behav. Brain Res. 133, 135-141.

Muir, J. L., Everitt, B. J., and Robbins, T. W. (1996). The cerebral cortex of the rat and visual attentional function: dissociable effects of mediofrontal, cingulate, anterior dorsolateral, and parietal cortex lesions on a fivechoice serial reaction time task. Cereb. Cortex 6, 470-481.

Paine, T. A., Neve, R. L., and Carlezon, W. A. Jr. (2009). Attention deficits and hyperactivity following inhibition of cAMP-dependent protein kinase within the medial prefrontal cortex of rats. Neuropsychopharmacology 34, 2143-2155.

Passetti, F., Chudasama, Y., and Robbins, T. W. (2002). The frontal cortex of the rat and visual attentional performance: dissociable functions of distinct medial prefrontal subregions. Cereb. Cortex 12, 1254-1268.

Passetti, F., Dalley, J. W., O'Connell, M. T., Everitt, B. J., and Robbins, T. W. (2000). Increased acetylcholine release in the rat medial prefrontal cortex during performance of a visual attentional task. Eur. J. Neurosci. 12, 3051-3058.

Pittenger, C., Fasano, S., MazzocchiJones, D., Dunnett, S. B., Kandel, E. R., and Brambilla, R. (2006). Impaired bidirectional synaptic plasticity and procedural memory formation in striatum-specific cAMP response element-binding protein-deficient mice. J. Neurosci. 26, 2808-2813.

Pliakas, A. M., Carlson, R. R., Neve, R. L., Konradi, C., Nestler, E. J., and Carlezon, W. A. Jr. (2001). Altered responsiveness to cocaine and increased immobility in the forced swim test associated with elevated cAMP response elementbinding protein expression in nucleus accumbens. J. Neurosci. 21 , 7397-7403.

Porte, Y., Buhot, M. C., and Mons, N. E. (2008). Spatial memory in the Morris water maze and activation of cyclic AMP response elementbinding (CREB) protein within the mouse hippocampus. Learn. Mem. $15,885-894$.

Rescorla, R. A., and Solomon, R. L. (1967). Two-process learning theory: relationships between Pavlovian conditioning and instrumental learning. Psychol. Rev. 74, 151-182.

Robbins, T. W. (2002). The 5-choice serial reaction time task: behavioural pharmacology and functional neurochemistry. Psychopharmacology (Berl.) 163, 362-380.

Rogers, R. D., Baunez, C., Everitt, B. J., and Robbins, T. W. (2001). Lesions of the medial and lateral striatum in the rat produce differential deficits in attentional performance. Behav. Neurosci. 115, 799-811.

Rosvold, H. E., Mirsky, A. F., Saranson, I., Bransome, E. B., and Beck, L. H. (1956). A continuous test of brain damage. J. Consult. Psychol. 20, 343-350.

Stanciu, M., Radulovic, J., and Spiess, J. (2001). Phosphorylated cAMP response element binding protein in the mouse brain after fear conditioning: relationship to Fos production. Brain Res. Mol. Brain Res. 94, 15-24. 
Sun, H., Green, T. A., Theobald, D. E., Birnbaum, S. G., Graham, D. L., Zeeb, F. D., Nestler, E. J., and Winstanley, C. A. (2010). Yohimbine increases impulsivity through activation of cAMP response element binding in the orbitofrontal cortex. Biol. Psychiatry 67, 649-656.

Tanaka, S. C., Balleine, B. W., and O’Doherty, J. P. (2008). Calculating consequences: brain systems that encode the causal effects of actions. J. Neurosci. 28, 6750-6755.

Tanis, K. Q., Duman, R. S., and Newton, S. S. (2008). CREB binding and activity in brain: regional specificity and induction by electroconvulsive seizure. Biol. Psychiatry 63, 710-720.

Vianna, M. R., Barros, D. M., Silva, T., Choi, H., Madche, C., Rodrigues, C., Medina, J. H., and Izquierdo, I. (2000). Pharmacological demonstration of the differential involvement of protein kinase $\mathrm{C}$ isoforms in short- and long-term memory formation and retrieval of one-trial avoidance in rats. Psychopharmacology (Berl.) 150, 77-84.

Wallace, D. L., Han, M. H., Graham, D. L., Green, T. A., Vialou, V., Iniguez, S. D., Cao, J. L., Kirk, A., Chakravarty, S., Kumar, A., Krishnan, V., Neve, R. L., Cooper, D. C., Bolaños, C. A., Barrot, M., McClung, C. A., and Nestler, E. J. (2009). CREB regulation of nucleus accumbens excitability mediates social isolation-induced behavioral deficits. Nat. Neurosci. 12, 200-209.

Wilkinson, L. S., Dias, R., Thomas, K. L., Augood, S. J., Everitt, B. J., Robbins, T. W., and Roberts, A. C. (1997). Contrasting effects of excitotoxic lesions of the prefrontal cortex on the behavioural response to D-amphetamine and presynaptic and postsynaptic measures of striatal dopamine function in monkeys. Neuroscience 80, 717-730.

Wilkinson, R. T. (1963). Interaction of noise with knowledge of results and sleep deprivation. J. Exp. Psychol. 66, 332-337.

Yin, H. H., Ostlund, S. B., and Balleine, B. W. (2008). Rewardguided learning beyond dopamine in the nucleus accumbens: the integrative functions of cortico-basal ganglia networks. Eur. J. Neurosci. 28, 1437-1448.

Yin, H. H., Ostlund, S. B., Knowlton, B. J., and Balleine, B. W. (2005). The role of the dorsomedial striatum in instrumental conditioning. Eur. J. Neurosci. 22, 513-523

Conflict of Interest Statement: The authors declare that the research was conducted in the absence of any commercial or financial relationships that could be construed as a potential conflict of interest.

Received: 03 July 2011; accepted: 21 September 2011; published online: 12 October 2011.

Citation: Pozzi L, Sacchetti G, Agnoli L, Mainolfi $P$, Invernizzi RW and Carli $M$ (2011) Distinct changes in CREB phosphorylation in frontal cortex and striatum during contingent and noncontingent performance of a visual attention task. Front. Behav. Neurosci. 5:65. doi: 10.3389/fnbeh.2011.00065

Copyright (C) 2011 Pozzi, Sacchetti, Agnoli, Mainolfi, Invernizzi and Carli. This is an open-access article subject to a non-exclusive license between the authors and Frontiers Media SA, which permits use, distribution and reproduction in other forums, provided the original authors and source are credited and other Frontiers conditions are complied with. 